Int. J. Morphol.,

31(1):23-30, 2013.

\title{
Quantitative Morphology Update: Image Analysis
}

\author{
Actualización de Morfología Cuantitativa: Análisis de Imagen
}

Caroline Fernandes-Santos; Vanessa Souza-Mello; Tatiane da Silva Faria \& Carlos Alberto Mandarim-de-Lacerda

FERNANDES-SANTOS, C.; SOUZA-MELLO, V.; FARIA, S. T.; MANDARIM-DE-LACERDA, C. A. Quantitative morphology update: Image analysis. Int. J. Morphol., 31(1):23-30, 2013.

SUMMARY: Quantitative morphology is a reliable tool in developmental, clinical and aging biology. Quantitative data of histological improvement and/or impairment due to dietary manipulations or pharmacological interventions draws the attention of countless researchers worldwide. Morphometry allows a wide range of two-dimension analysis to be performed, whereas image segmentation allows the measurement of a single structure or the determination of the intensity of its color after adequate immunostaining or even the area occupied by a specific sort of cell. When it comes to unbiased analysis, consideration should be given to suitable tissue perfusion, fixation and embedding, avoiding artifacts. Furthermore, tissue shrinkage should be taken into account. In order to ensure reproducibility, one of the most important principles in scientific research, and to allow different groups to be compared, image acquisition and image segmentation emerge as crucial steps and should be standardized. This paper aims to approach some important care for appropriate tissue processing and evaluation, and shows some practical examples of how morphometry and image segmentation can be applied to your experiment.

KEY WORDS: Quantitative morphology; Image analysis.

\section{INTRODUCTION}

Quantitative morphology is a reliable tool in developmental, clinical and aging biology. The quantification of morphological changes in histological samples might be of great help to evaluate the progression of degenerative diseases and the effect of pharmacologic and dietary manipulation in animals. Morphometry is based on geometric principles in the two-dimension, and offers a wide range of options for analyzing tissue morphology (Aherne and Dunnill, 1982). On the other hand, image segmentation allows the quantification of a single structure if its color is from far different from the remaining structures of the tissue (Mandarim-de-Lacerda et al., 2010). However, some basic principles must be followed for appropriate data collection in order to guarantee reproducibility. Therefore, researchers working on the same research field will be able to generate unbiased and comparable data.

Scientists often use two or more groups, each having a specific purpose. For example, a group of hypertensive rats can be compared with a group of normotensive ones, where the main purpose is to analyze the hypertrophy of the aorta wall. How could this parameter be assessed?
Morphometry can be used to measure the artery wall thickness of normotensive and hypertensive animals, generating several measures that can be later statistically compared (Fernandes-Santos et al., 2009c). Another example would be the evaluation of adipocyte diameter of inguinal fat pad from lean and obese mice, in order to evaluate hypertrophy (Fernandes-Santos et al., 2009a). Regarding image segmentation, it can be used for instance to quantify the area occupied by b-cells in a pancreatic islet. Beta cells can be stained with an antibody against insulin. Further, the stain is segmented and the insulin-stained area is then analyzed in the segmented image (Fernandes-Santos et al., 2009b).

The present paper will approach some important care for appropriate tissue processing and evaluation, and will give some practical examples of how morphometry and image segmentation can be applied to your experiment. There are a number of softwares available for morphometry analysis and image segmentation, The examples shown here are based on the software Image-Pro Plus (Media Cybernetics, Inc). 


\section{Image acquisition}

Reproducibility is one of the most important principles in scientific research. Data acquisition must follow a straight and detailed protocol so that anybody at any time can redo the same steps, and then obtain reproducible results. For this reason, some important aspects have to be taken into account before making any kind of measurement.

1.1 Histological artifact. Artifact is the modification of tissue morphology due to inappropriate processing and/or embedding. In a control animal, it is easy to identify a histological artifact. However, if the animal is submitted to a specific procedure (e.g. treatment with a drug), it is harder to identify if the change in tissue morphology is a result of either intervention or tissue artifact.

Fixation is a step during tissue processing that usually leads to histological artifacts. Fixation can be done by either immersing the sample into a fixative solution or by perfusing the vascular system through the heart. In the first case, if the sample is too large, its outer part may be fixed, whereas its inner part may not. As a consequence, the core and the boundary of the tissue will seem unlike on the light microscope. In the second case, a high perfusion pressure can enlarge the lumen size of vascular structures. On the microscope, it is easily recognized as dilated capillaries in the heart (intramyocardial capillaries), or dilated glomerular capillaries and tubes in the kidney.

1.2 Tissue shrinkage. Tissue embedding is a critical step since it changes tissue volume because of retraction of the embedding medium during its hardening (Dorph-Petersen et al., 2001; Gardella et al., 2003). As a result, measurements will be smaller than measures taken in vivo. To avoid this bias, a pilot study can be done in order to assess the percentage of tissue shrinkage during embedding, and this factor can be later used to correct the measures acquired from the shrunk tissue. The percentage of tissue shrinkage can be assessed by the ratio of tissue volume before and after fixation and embedding. Tissue volume can be assessed by the Cavaliere's method (Scherle, 1970; Mandarim-deLacerda et al., 2010).

1.3 Morphometry of contractile tissues. Smooth muscle cells and cardiomyocytes are contractile cells. Depending on the physiological condition in vivo, they are contracted or relaxed, so their morphology varies regarding length and volume. It can be a problem, for instance, if the aim is to analyze the tunica media thickness of an elastic artery such as the aorta. To avoid it, a 10\% potassium chloride solution can be administered into the cardiovascular system when the animal is being killed, because it guarantees that all muscle cells will be at the non-contracted state (Torres $e t$ al., 2008).

1.4 System calibration. Tissue image is converted into a numeric form during digitalization. This process divides an image into a horizontal grid, or array, of very small regions called picture elements, or pixels. In the computer, the image is represented by this digital grid, or bitmap, where each pixel is identified by its position in the grid. The length of a measure is determined by the number of pixels along the line, and the area of an defined object is determined by the number of pixels within the outlined area, and so forth (Barba et al., 1992).

It is important that pixels be related with the metric scale in order to obtain a palpable measure, and an object micrometer is commonly used for this purpose. It consists of a glass slide with a 1 millimeter rule divided into 1/100 parts, so its smaller part represents 10 micrometers. A digital image from the object micrometer can be acquired, then a straight line is drawn over the scale, and the length of this line is informed to the software. Finally, the software correlates the length (e.g. 50 micrometers) with the number of pixels contained on it. If the software is informed about the magnification of this measure (e.g. objective 40x), any further measurement obtained at this same magnification is promptly converted from pixels to micrometers (Mandarimde-Lacerda et al., 2010).

\section{Morphometry}

It is easy to understand the relevance of morphometry in studies regarding development (Catta-Preta et al., 2006), aging process (Aguila \& Mandarim-deLacerda, 2001), and pathological diagnosis (Simmons, 2011). Morphometric tools are also valuable in basic scientific research because they allow the evaluation of tissue remodeling in organs such as the heart and aorta (Silva-Junior et al., 2011), adipose tissue (Bringhenti et al., 2010), pancreas (Marques et al., 2010; Frantz et al., 2011), kidney (Cunha et al., 2008), and uterus (Brasil et al., 2005). In pathological diagnosis, the role for morphometry in kidney tumor evaluation has been criticized by some as unnecessary and impractical. Actually, these systems may prove valuable to surgeons who conduct partial nephrectomy on a routine basis because they provide a quantitative and standardized indication of tumor complexity and partial nephrectomy difficulty (Simmons, 2011).

Morphometry is a two-dimensional quantitative method that uses a caliper (mainly a caliper micrometer, a gauge with a calibrated micrometer screw for the measurement of thin objects under microscopic 
observation). It allows the study of changes in shape and size of particular structures in a tissue section. A stained section from any tissue can be easily evaluated regarding the lengths, perimeters, and areas of its structures using appropriate software. Below there are some examples of how morphometry can be applied to your experiment.

2.1 Length. Length is obtained by drawing a straight line on the structure that needs to be measured. If the software knows the objective from which the image was acquired, the length of the line is related to the number of pixels on it, and an information in the metric system is generated (for instance, $15(\mathrm{~m})$. The length tool can be used to assess the diameter of cells and structures, such as adipocytes (Fig. 1), renal glomerulus and pancreatic islets (Fig. 1). The thickness of an artery wall and its lumen diameter can also be measured using this tool. Another way to measure length is by the polygon tool. For instance, a polygon drew over the arterial intima layer represents its lumen perimeter. In order to obtain more reliable measurements, nearly round to spherical structures should have at least two perpendicular measures obtained, passing through their equatorial plane (Fig. 1).

2.2 Area. The area of a structure is obtained by drawing a line over its external outline. To delimit an area, tools such as the circle, rectangle and polygon can be used depending on the shape of the structure. Area is easily calculated within these geometrical forms, as the software correlates it with the number of enclosed pixels. For instance, the renal glomerulus has a nearly spherical shape; its cross-sectional area can be measured by drawing a circle over its Bowman's capsule. Another example is the measuring of the area of a pancreatic islet. It is nearly round in shape, and its area can be measured by drawing a polygon over its outline. The outer cross-sectional area of an arterial branch can be also obtained by drawing a polygon over the adventitia layer.

2.3 Practical example: Aorta morphometry. There is several information that can be obtained from a cross-section image of an artery such as the aorta: tunica media and intima thickness, lumen diameter, lumen perimeter, lumen area and tunica media cross-sectional area. Some of them are explained below.

For this example, tunica media (TM) will be defined as the region delimited by the inner and external elastic laminas. Using the length tool, a line nearly perpendicular to these two elastic laminas can be drawn, and then the media thickness is obtained. As the cut done to generate the aorta ring can be nearly oblique, four measures per ring should be obtained at 0, 90, 180 and 270 degrees. Thus, the average of
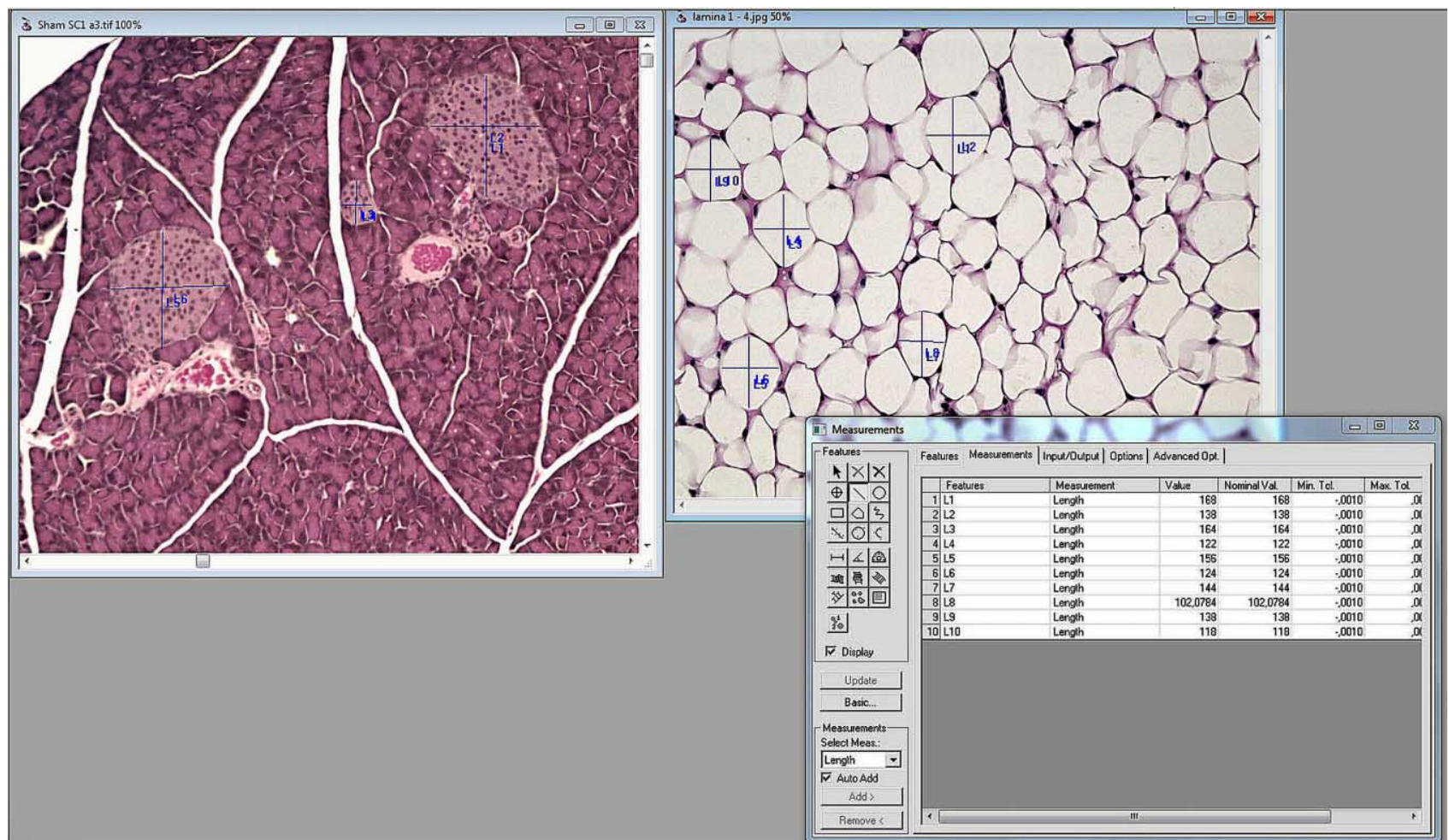

Fig. 1. Aorta section stained with hematoxilin \& eosin. The line tool (in blue) was used to measure the major and minor diameters of mice pancreatic islets (left) and adipocytes (right) by the software Image Pro Plus. Values are given in the "Measurements" box on the lower right side corner. 

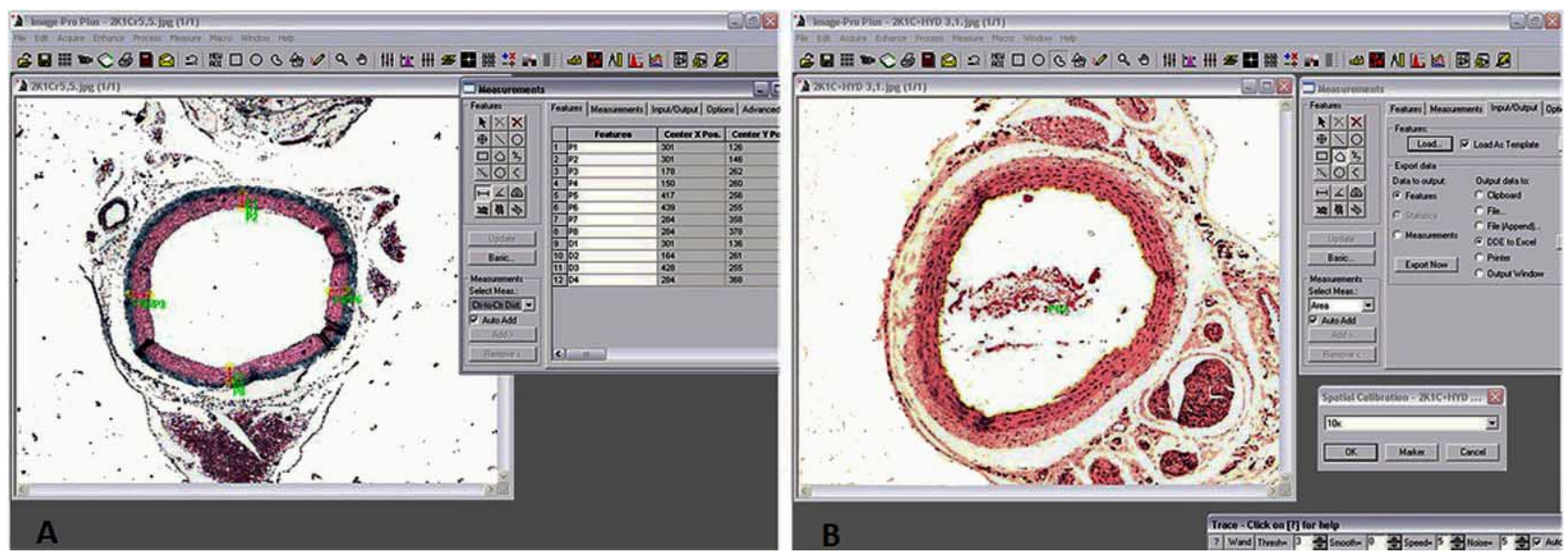

Fig. 2. Cross section images from mice aorta. (A) The length tool (in red) was used to delineate a straight line nearly perpendicular to both internal and external elastic laminae. Its length represents the tunica media thickness. (B) A line was drawn on the tunica intima using the polygon tool (yellow) to assess lumen area.

these four measures will correlate better with the real thickness of the tunica media (Fig. 2A) (Fernandes-Santos et al., 2009c).

Lumen area (a) can be estimated by drawing a polygon over the inner face of the intima layer. Then, lumen diameter (d) can be obtained as $d=2 \sqrt{a} / \mathrm{p}$, where $\mathrm{p}$ is equal to 3.14. The mean cross-sectional area of the intima plus tunica media (IMA, intima-media area) can be estimated as IMA $=([p(d / 2+I M T) 2]-[p(d / 2) 2])$, where IMT represents the sum of intima and media thickness (Fig. 2B) (FernandesSantos et al., 2009c).

\section{Image segmentation}

Image segmentation comprises methods that enable the precise quantification or measurement of a broad range of structures. It can be defined as the process of partitioning an image into multiple regions, typically with the aim of identifying objects or boundaries, being the latter more challenging (Anderson \& Barrett, 2009; Mandarim-deLacerda et al., 2010). Once segmented, data such as the area occupied by an object, its size or the percentage of density is typically straightforward to extract.

Segmentation is performed by identifying colors and isolating them from the whole image. For that reason, suitable staining is crucial to obtain a reliable result. Objects of interest for quantification or measurement should be stained with a color that differs significantly from the remaining tissue to facilitate pixel detection by the software. Consideration should be given to other structures showing similar color intensity, which might be segmented as well, adding bias to the analysis.
Pixel selection is controlled by a threshold tool. After segmentation of the image, it reduces color images to black and white. It is possible by choosing a range of intensities to be highlighted (set to white) and turning all the remaining tissue to be black, which will not be considered for the analysis.

\subsection{Image acquisition}

In color images, it is crucial that features to be segmented have a color as different as possible from the remaining tissue, in order to make their identification easier by the software. If the remaining features of the tissue have pixels similar to that found in the feature to be segmented, they will be all segmented, thus creating background. For example, the hematoxylin and eosin stain in the myocardium results in a tissue broadly stained as pink. If the aim is to threshold muscle cells of intramyocardium arteries, not only they will be segmented, but all cardiomyocytes as well (Motta and Mandarim-de-Lacerda, 2012). A better approach would be, for instance, to stain cardiac collagen fibers by Masson's trichrome, which highlights collagen fibers as blue, whereas the remaining tissue is mainly red or dark red. Fibers can be easily identified by the software, and the segmented image will show no background.

\subsection{Segmentation}

Image-Pro Plus software offers two different ways to perform segmentation: histogram-based (HB) or color-cube-based (CCB). In the former, all pixels within the image based on RGB or HIS color models are depicted into a histogram. Following the selection of the range of pixels that encompasses the object of interest, a new black-and-white 


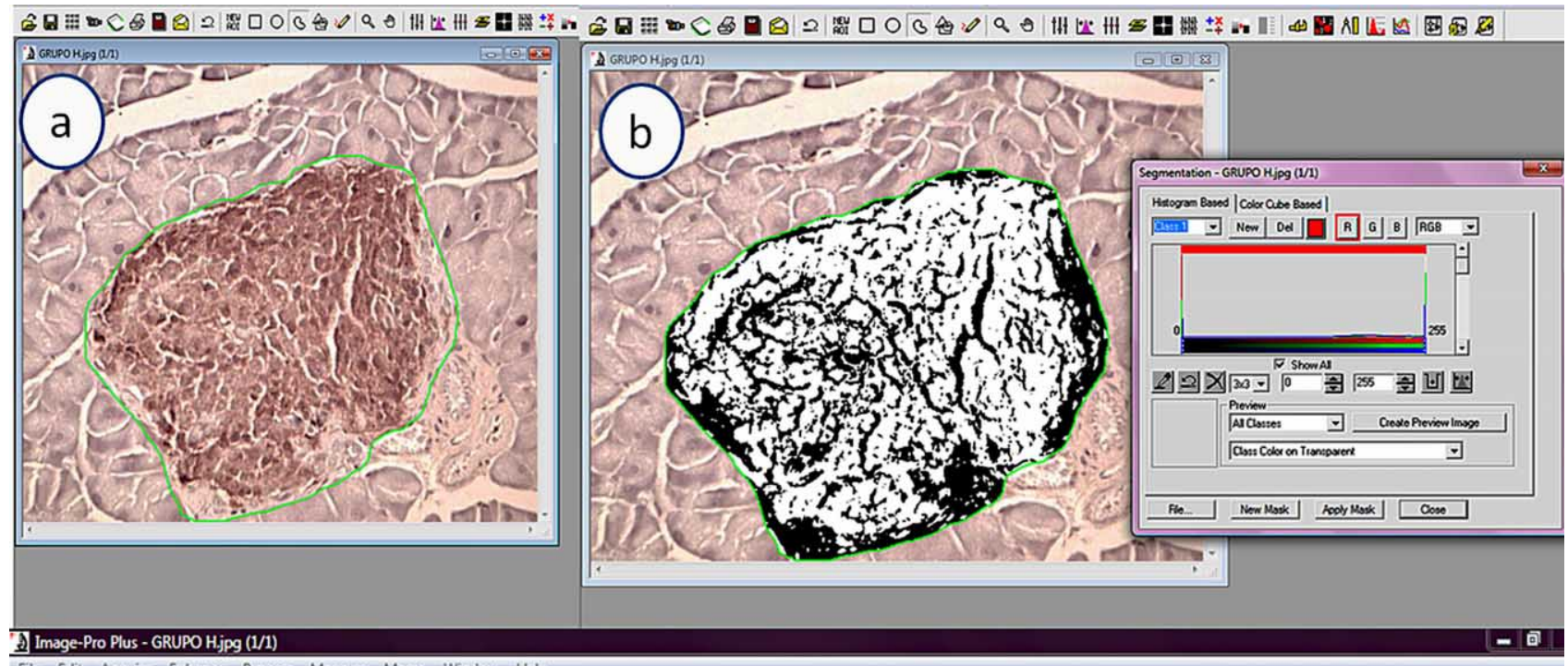

File Edit Acquire Enhance Process Messure Macro Window Help

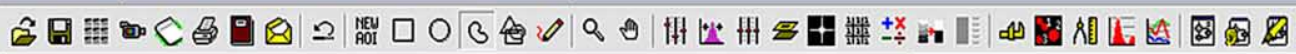

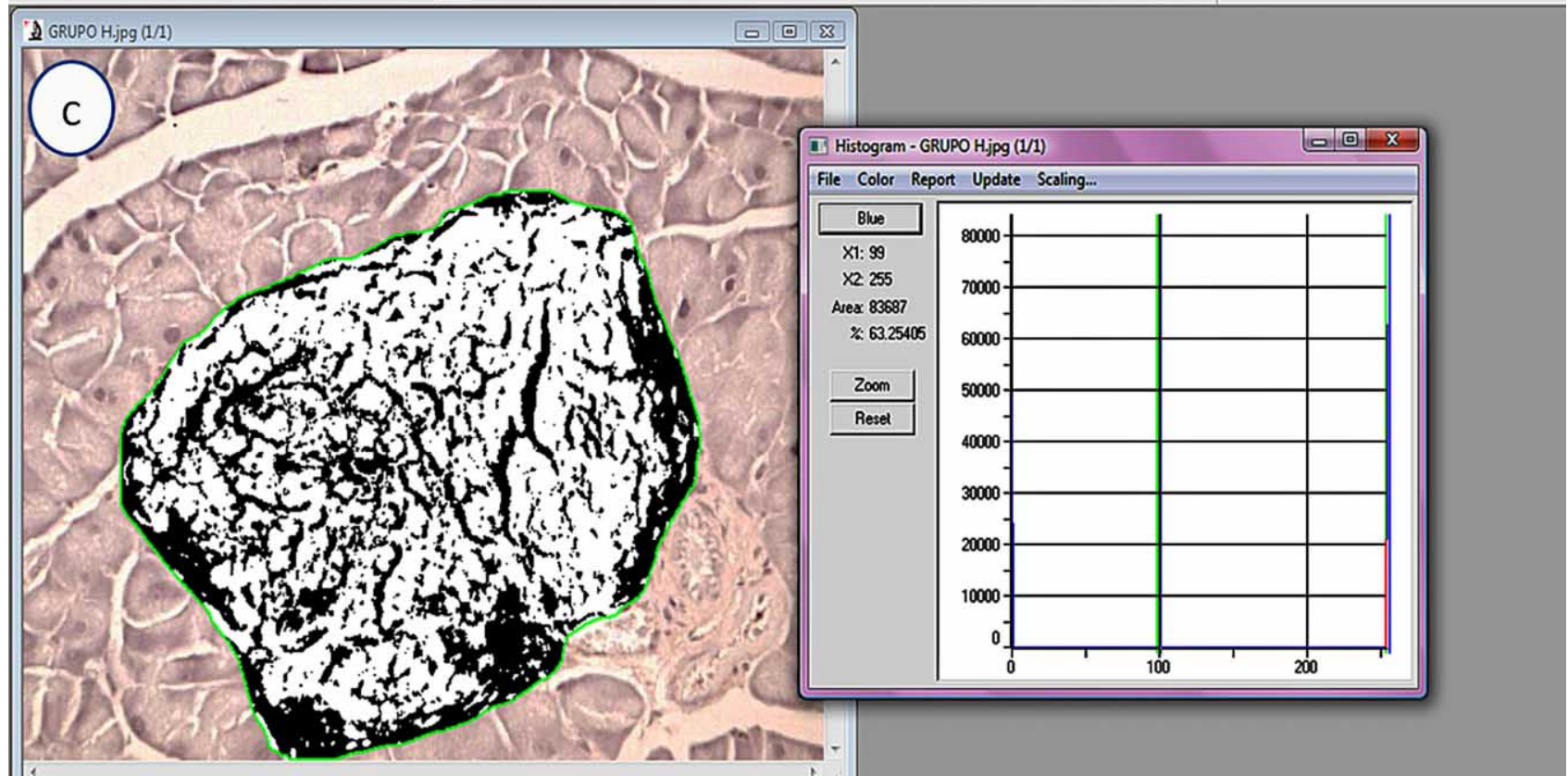

Fig. 3. Segmentation and quantification of a digital image from mouse pancreas. (A) Pancreatic islet stained with anti-insulin antibody (in brown, beta cell), and the AOI tool was used to delimitate islet boundary; (B) The segmentation box is open (color-cube-based mode) and a new image in black and white was generated; (C) The density of the insulin-stained area per islet (as percentage) is measured in the black and white image by the histogram tool.

image is generated, where white areas represent structures to be evaluated while black zones comprise the remaining tissue. HB segmentation option is useful to segmentation of nearby pixels.

On the other hand, when objects to be selected are widespread, CCB is more suitable once pixel choice for segmentation can be made manually, avoiding underestimation. Figure 3 shows the segmentation of insulin stained mouse pancreatic islets (insulin refers to the brown stained area in the core of the islet, 3A). Segmentation option was CCB mode, and after the selection of all pixels stained with varied intensities of brown, a mask tool is applied and in the new image, white areas correspond to insulin positive areas, whereas black areas correspond to the remaining endocrine and the exocrine pancreas (Fig. 3B). 


\section{Final remarks}

When combined with adequate image acquisition and labeling, important quantitative results can be achieved. After proper segmentation, quantification is performed through the histogram tool, which allows inferring the area occupied by white (object of interest) and black areas. A histogram tool is made up of a scale ranging from 0 to 255 (Fig. 4A), where 0 is white, 255 is black, and the remaining values (1254) refer to gray scale, with a wide variety of gray intensities. As the segmented image does not present any kind of gray color, 0 and 255 represent the total percentage of white and black color, respectively, and their sum is 100\%. If adequate calibration can be assured, the histogram could also offer the total area occupied by insulin staining or oil red staining (Fig. 5), implying insulin secretion by pancreatic islets or percentage of hepatic steatosis. Taking into account the islet example, islet boundary can be drawn using the area of the interest (AOI) tools. Consequently, the percentage obtained will refer to the density area per islet of insulin stain (Fig. 3C) (Fernandes-Santos et al., 2009b).

Figure 4 refers to rat aortic wall stained with orcinol, which shows elastic fibers as pink and the remaining tissue with different color. Image segmentation can be used for the quantification of the density per area of elastic fibers. In order to perform this, the pink color is selected and then segmented. Afterwards, a polygon is drawn (AOI tool) into the segmented image and the media layer is delineated. Inside this selected area, the histogram tool can be used to determine the percentage and area of elastic fibers (FernandesSantos et al., 2009c).
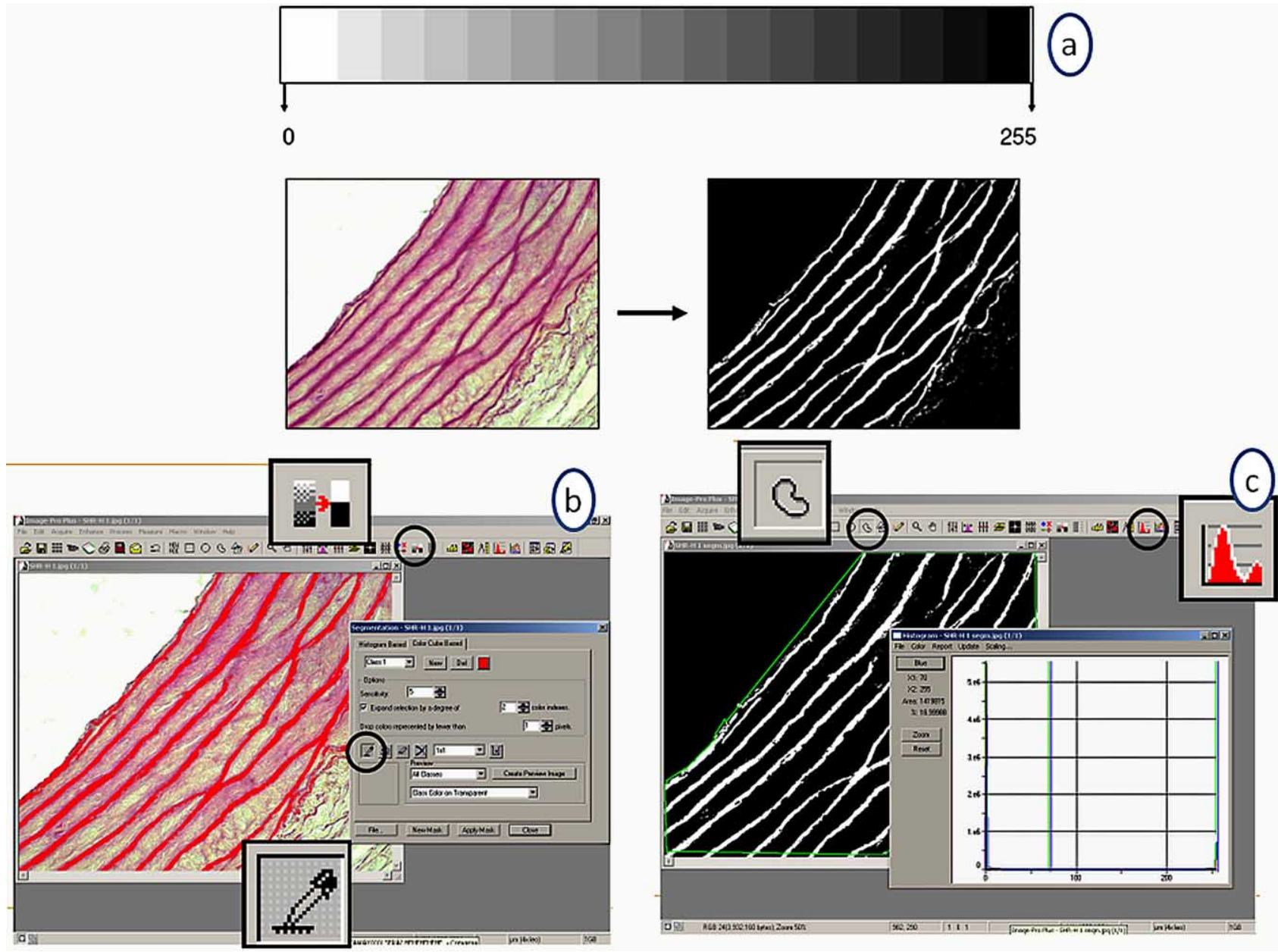

Fig. 4. Segmentation and quantification of a digital image from rat aorta. (A) Scale varying from zero (white) to 255 (black), showing intermediate gray scale (upper image). Elastic fibers are stained as pink by orcinol (bottom left). (B) Segmentation using the color cubebased mode. (C) Determination of density per area of elastic fibers through the polygon tool (upper right) that was drawn using AOI tool (upper left) on the segmented image so as to delineate the media layer of the aorta. Both percentage and area of elastic fibers were determined within the segmented image. 


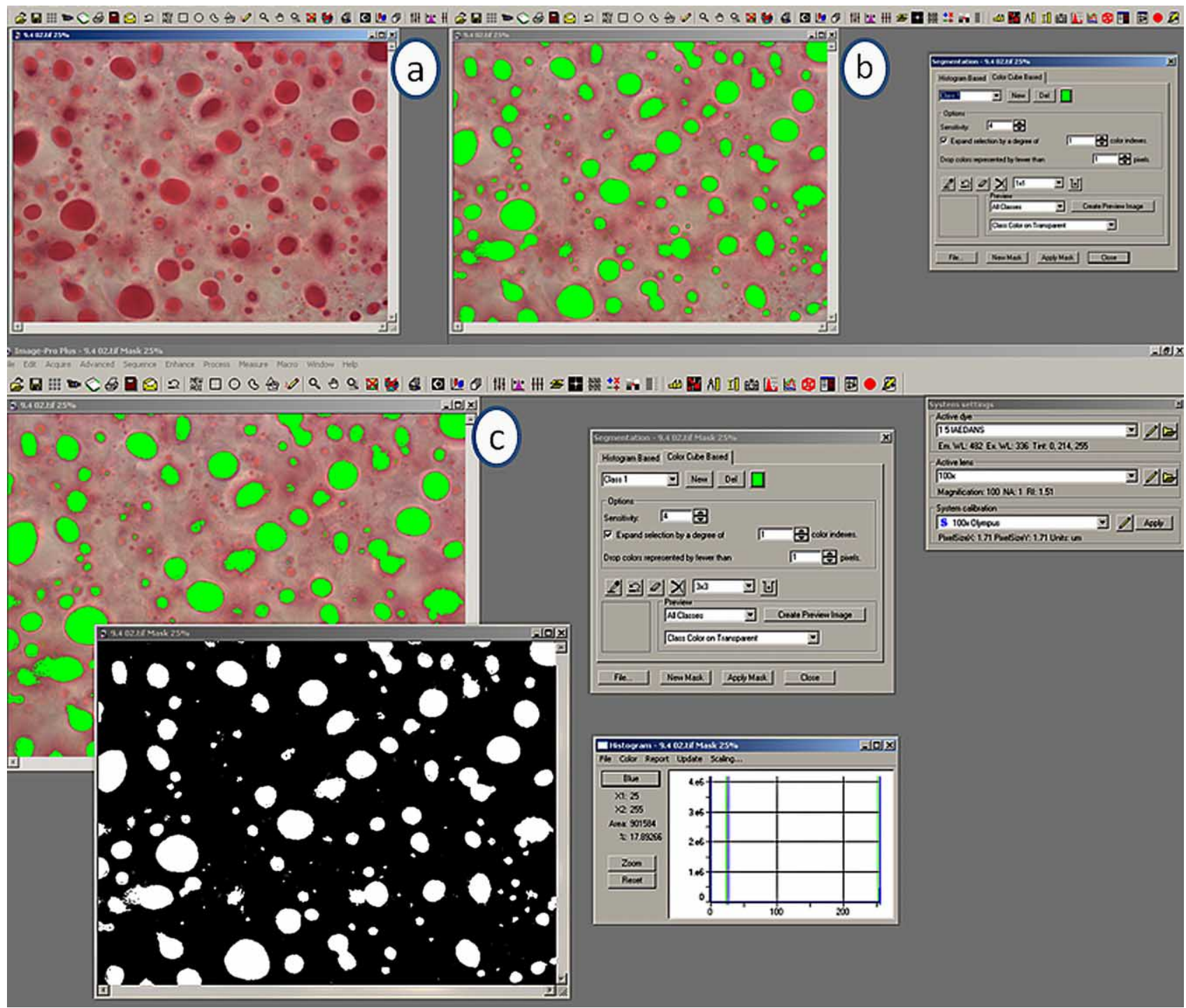

Fig. 5. Quantification of hepatic steatosis in Oil red-stained sections. (A) Lipid droplets are stained with Oil red (in red); (B) Lipid droplets were selected (in green) using the color cubed-based tool; (C) A mask was applied, the image segmented in black and white, and the white area was quantified using the histogram tool (white represents lipid droplets).

ACKNOWLEDGEMENTS. The authors are supported by Brazilian agencies CNPq (Ministry of Science and Technology), CAPES (Ministry of Education) and FAPERJ (Foundation of the State of Rio de Janeiro for Support Scientific Research).

FERNANDES-SANTOS, C.; SOUZA-MELLO, V.; FARIA, ST; MANDARIM-DE-LACERDA, C.A. Actualización de morfología cuantitativa: análisis de las imágenes. Int. J. Morphol., 31(1):23-30, 2013.

RESUMEN: La morfología cuantitativa es una herramienta confiable en la biología del desarrollo, clínica y en el envejecimiento. Los innumerables datos cuantitativos de mejoras histológica y / o deterioro debido a las manipulaciones dietéticas o intervenciones farmacológicas atraen la atención de los investigadores en todo el mundo. La morfometría permite realizar una amplia gama de análisis en dos

dimensiones, mientras que la segmentación de imágenes permite la medición de una única estructura o la determinación de la intensidad de su color después de una adecuada inmunotinción o incluso el área ocupada por un tipo específico de célula. Cuando se trata de un análisis imparcial, debe considerarse la posibilidad de la perfusión tisular adecuada, fijación e inclusión, evitando artefactos. Además, se debe considerar la contracción del tejido. Con el fin de asegurar la reproducibilidad, uno de los principios más importantes en la investigación científica, y para permitir que diferentes grupos se comparen, la adquisición y segmentación de la imagen aparecen como pasos cruciales y deben ser estandarizados. En este trabajo se abordan algunos cuidados importantes para el procesamiento de tejidos y evaluación apropiadas, y se muestran algunos ejemplos prácticos de cómo la segmentación morfométrica y la imagen se pueden aplicar a su experimento.

PALABRAS CLAVE: morfología cuantitativa, análisis de imagen. 


\section{REFERENCES}

Aguila, M.B. \& Mandarim-de-Lacerda, C. A. Blood pressure, ventricular volume and number of cardiomyocyte nuclei in rats fed for 12 months on diets differing in fat composition. Mech. Ageing Dev., 122(1):77-88, 2001.

Aherne, W. A. \& Dunnill, M. S. 1982. Morphometry. London, Edward Arnold Publishers.

Anderson, J. R. \& Barrett, S. F. Graphical user interface to optimize image contrast parameters used in object segmentation biomed 2009. Biomed. Sci. Instrum., 45:173-8, 2009.

Barba, J.; Chan, K. S. \& Gil, J. Quantitative perimeter and area measurements of digital images. Microsc. Res. Tech., 21(4):300-14, 1992.

Brasil, F. B.; Faria, T. S.; Costa, W. S.; Sampaio, F. J. \& Ramos, C. F. The pups' endometrium morphology is affected by maternal malnutrition during suckling. Maturitas, 51(4):405-12, 2005.

Bringhenti, I.; Schultz, A.; Rachid, T.; Bomfim, M. A.; Mandarimde-Lacerda, C. A. \& Aguila, M. B. An early fish oil-enriched diet reverses biochemical, liver and adipose tissue alterations in male offspring from maternal protein restriction in mice. $J$. Nutr. Biochem., 2010.

Catta-Preta, M.; Oliveira, D. A.; Mandarim-de-Lacerda, C. A. \& Aguila, M. B. Adult cardiorenal benefits from postnatal fish oil supplement in rat offspring of low-protein pregnancies. Life Sci., 80(3):219-29, 2006.

Cunha, A. R.; Aguila, M. B. \& Mandarim-de-Lacerda, C. A. Effects of early postnatal hyperglycaemia on renal cortex maturity, endothelial nitric oxide synthase expression and nephron deficit in mice. Int. J. Exp. Pathol., 89(4):284-91, 2008.

Dorph-Petersen, K. A.; Nyengaard, J. R. \& Gundersen, H. J. Tissue shrinkage and unbiased stereological estimation of particle number and size. J. Microsc., 204(Pt 3):232-46, 2001.

Fernandes-Santos, C.; Carneiro, R. E.; Mendonca, L. S.; Aguila, M. B. \& Mandarim-de-Lacerda, C. A. Pan-PPAR agonist beneficial effects in overweight mice fed a high-fat highsucrose diet. Nutrition, 25(7-8):818-27, 2009a.

Fernandes-Santos, C.; Carneiro, R. E.; Mendonca, L. S.; Aguila, M. B. \& Mandarim-de-Lacerda, C. A. Rosiglitazone aggravates nonalcoholic fatty pancreatic disease in C57BL/6 mice fed high-fat and high-sucrose diet. Pancreas, 38(3):e80-6, $2009 \mathrm{~b}$.

Fernandes-Santos, C.; Mendonca, L.S. \& Mandarim-de-Lacerda, C.A. Favorable cardiac and aortic remodeling in olmesartantreated spontaneously hypertensive rats. Heart Vessels, 24(3):219-27, 2009
Frantz, E. D.; Aguila, M. B.; Pinheiro-Mulder, A. R. \& Mandarimde-Lacerda, C. A. Transgenerational endocrine pancreatic adaptation in mice from maternal protein restriction in utero. Mech. Ageing Develop., 132(3):110-6, 2011.

Gardella, D.; Hatton, W. J.; Rind, H. B.; Rosen, G. D. \& von Bartheld, C.S. Differential tissue shrinkage and compression in the z-axis: implications for optical disector counting in vibratome-, plasticand cryosections. J. Neurosci. Methods, 124(1):45-59, 2003.

Mandarim-de-Lacerda, C. A.; Fernandes-Santos, C. \& Aguila, M. B. Image analysis and quantitative morphology. Methods Mol. Biol., 611:211-25, 2010.

Marques, C. M.; Motta, V. F.; Torres, T. S.; Aguila, M. B. \& Mandarim-de-Lacerda, C. A. Beneficial effects of exercise training (treadmill) on insulin resistance and nonalcoholic fatty liver disease in high-fat fed C57BL/6 mice. Braz. J. Med. Biol. Res., 43(5):467-75, 2010.

Motta, V. F. \& Mandarim-de-Lacerda, C. A. Beneficial effects of exercise training (treadmill) on body mass and skeletal muscle capillaries/myocyte ratio in C57BL/6 mice fed high-fat diet. Int. J. Morphol., 30(1):205-12, 2012.

Scherle, W. A simple method for volumetry of organs in quantitative stereology. Mikroskopie, 26(1):57-60, 1970.

Silva-Junior G. O.; Torres, T. S.; Mendonca, L. S. \& Mandarim-deLacerda, C. A. Rosiglitazone (peroxisome proliferator-activated receptor-gamma) counters hypertension and adverse cardiac and vascular remodeling in 2K1C hypertensive rats. Exp. Toxicol. Pathol., 63(1-2):1-7, 2011.

Simmons, M.N. Morphometric characterization of kidney tumors. Curr. Opin. Urol., 21(2):99-103, 2011.

Torres, T. S.; Silva, G. D.; Aguila, M. B.; Carvalho, J. J. \& Mandarimde-Lacerda, C. A. Effects of rosiglitazone (a peroxysome proliferator-activated receptor gamma agonist) on the blood pressure and aortic structure in metabolically programmed (perinatal low protein) rats. Hypertens Res., 31(5):965-75, 2008.

Correspondence to:

Laboratório de Morfometria

Metabolismo e Doença Cardiovascular

Centro Biomédico, Instituto de Biologia

Universidade do Estado do Rio de Janeiro

Av 28 de Setembro 87 fds, 20551- 030

Rio de Janeiro, RJ

BRASIL

Tel: +55 $212868-8316$

Fax: 2868-8033

E-mail: mandarim@uerj.br

URL: www.Immc.uerj.br

Received: 26-07-2012

Accepted: 26-11-2012 